\title{
Questes
}

vestes Revue pluridisciplinaire d'études médiévales

\section{La route des pèlerins : conclusion}

\section{Magali Cheynet}

\section{(2) OpenEdition}

\section{Journals}

\section{Édition électronique}

URL : http://journals.openedition.org/questes/1434

DOI : 10.4000/questes.1434

ISSN : 2109-9472

\section{Éditeur}

Les Amis de Questes

\section{Édition imprimée}

Date de publication : 15 novembre 2011

Pagination : 93-96

ISSN : 2102-7188

\section{Référence électronique}

Magali Cheynet, «La route des pèlerins : conclusion », Questes [En ligne], 22 | 2011, mis en ligne le 01 janvier 2014, consulté le 15 septembre 2020. URL : http://journals.openedition.org/questes/1434 


\section{Conclusion}

Magali CHEYNET

Le projet du séminaire a évolué en cours de route : parties du désir d'approcher les conditions matérielles du pèlerinage, les contributions se sont ordonnées sur l'axe dynamique de la route elle-même. Différents pèlerins sillonnent des routes tantôt communes, tantôt singulières. Ainsi, comme le montre Céline Ménager ${ }^{1}$, l'impératrice Hélène ouvre en partant pour Jérusalem la voie d'un pèlerinage qui a exercé une grande fascination aussi bien sur les hommes que sur les femmes du Moyen Âge. Son parcours fonde aussi un modèle pour un groupe particulier, celui des riches matrones romaines: tout comme il s'inscrit dans un jeu d'intérêts politiques collectifs, le trajet individuel d'Hélène forge une identité commune. Une ligne de force qui traverse les contributions rassemblées se fait jour ici, celle de l'identité de ces pèlerins. Il serait facile en effet de céder à l'illusion créée par le costume que portent tous les pèlerins et de raisonner en termes généralisants. Leur statut de pénitent donne l'impression d'absorber leur identité propre: alors que les vêtements soulignent normalement le rang social de l'individu, ici ils tendent à l'effacer. C'est d'ailleurs l'un des ressorts de l'allégorisation que Carine Giovénal a étudiée $^{2}$ : sous la plume de Raoul de Houdenc, le parcours le plus singulier reflète une destinée commune, humaine, pour mieux interroger les choix individuels. Cette valeur générale de la pénitence est révélée par l'attitude des communautés hospitalières à l'égard de ceux qu'elles accueillent. Irène Strobbe rappelle que, sur les quatorze hôpitaux

\footnotetext{
${ }^{1}$ Voir dans ce bulletin la contribution de Céline MenAGER « Les femmes en Terre sainte aux $\mathrm{IV}^{\mathrm{e}}$ et $\mathrm{V}^{\mathrm{e}}$ siècles : une nouvelle piété pour les matrones romaines », p. 24-34.

${ }^{2}$ Voir dans ce bulletin la contribution de Carine GiOvenAL, "Le Songe d'Enfer de Raoul de Houdenc : voie de l'au-delà ou chemin d'ici-bas ? », p. 65-77.
} 
de Lille, seuls trois accueillent des pèlerins, ce qui indique que le statut de ces derniers est particulier par rapport à celui des pauvres ou des malades. Les hôpitaux qui ouvrent leurs portes aux pèlerins ne font en revanche pas de distinction entre leurs patients, ni, parfois, entre les patients et les soignants qui appartiennent temporairement à une même communauté3.

Cependant, les conditions matérielles du voyage traduisent la plus ou moins grande aisance du pèlerin et dessinent divers profils : l'ascèse est certes un idéal partagé par tous, mais elle n’est pas nécessairement mise en pratique et la différence est grande entre celui qui marche et celui qui peut chevaucher, celui qui porte toutes ses possessions dans sa besace et celui qui est suivi par un train de bagages. Le mode d'hébergement choisi est évidemment révélateur : Irène Strobbe souligne qu’à côté des trois hospices lillois dont elle a exploré les archives, des hôtels pouvaient accueillir les pèlerins et d'autres hébergements de fortune être improvisés par la ville en cas d'affluence exceptionnelle. Jean-Dominique Delle Luche rejoint le propos d'Irène Strobbe et de Céline Ménager pour montrer que, si l'on ne peut pas trancher entre une origine populaire et une origine aristocratique des pratiques du pèlerinage, les grands personnages sont présents sur les routes et encouragent telle ou telle pratique, par l'exemple personnel, l'établissement d'un hospice ou l'assurance de la sécurité des routes ${ }^{4}$.

Les contributions rassemblées peuvent ainsi être confrontées à des études sociologiques établissant des pourcentages de fréquentation: Charles et Luce Pietri estiment par exemple que les pèlerins venus à SaintMartin-de-Tours au cours de la deuxième moitié du $\mathrm{VI}^{\mathrm{e}}$ siècle sont essentiellement des personnes de rang social modeste (70\%), mais cela ne

\footnotetext{
${ }^{3}$ Voir dans ce bulletin la contribution d'Irène STROBBE, «Hôpitaux de fondation comtale et pèlerins à Lille à la fin du Moyen Âge », p. 50-64.

4 Voir dans ce bulletin la contribution de Jean-Dominique DelLE LuCHE, «Les pèlerinages dans le Saint-Empire à la fin du Moyen Âge : mises en perspective », p. 78-92.
} 
veut pas dire que tous sont de pauvres hères. Parmi les pèlerins venus honorer saint Martin se trouvent surtout des hommes (75\%), mais aussi des femmes et des enfants $(31 \%)^{5}$. Que des enfants aient pu parcourir les routes de pèlerinage est surprenant ; leur déplacement en larges groupes vers le Mont Saint-Michel constitue l'un des traits caractéristiques de ce pèlerinage, dont le côté spectaculaire était déjà au Moyen Âge un objet d'admiration ou de réprobation ${ }^{6}$. Si les différences de condition sociale sont bien perceptibles, il en va de même pour la différence entre hommes et femmes. Là encore le costume du pèlerin pourrait gommer les silhouettes, mais les articles de Céline Ménager, Irène Strobbe et Aurélie Houdebert ont mis en lumière quelques figures féminines, de sainte Hélène à Isabelle de Portugal, en passant par des personnages romanesques dont les motivations oscillent entre dévotion, désir profane et ruse féminine. Le corpus choisi par Aurélie Houdebert sort des sentiers battus et nous permet d'affiner les représentations littéraires de la pèlerine ${ }^{7}$ : les romans « du troisième type » exploitent certes des motifs hérités de la caricature traditionnelle dans la construction de leurs personnages féminins, mais ils ne relèvent pas du ton satirique adopté par exemple par les fabliaux. Par opposition aux tentatives de justification des menées de son héroïne que le roman d'Amadas et Ydoine ne condamne jamais, on songe par exemple à la caricature comique du fabliau Des Trois dames, dans lequel des femmes

\footnotetext{
${ }^{5}$ Charles et Luce PIETRI, « Le pèlerinage en Occident à la fin de l'Antiquité », in Henry Branthomme et Jean Chelini (dir.), Les Chemins de Dieu. Histoire des pèlerinages chrétiens des origines à nos jours, Paris, Hachette, «Pluriel », 8725, 1995 (1 ${ }^{\text {ère }}$ éd. 1982), partie I, chap. 3, p. 79-118 (cit. p. 106-108).

${ }^{6}$ Cf. Ilona HANS-COLLAS, « Le Mont Saint-Michel et les pèlerinages d'enfants au XIV ${ }^{\mathrm{e}}$ et au $\mathrm{XV}^{\mathrm{e}}$ siècle : sources françaises et germaniques ", in Giampietro CASIRAGHI et Giuseppe SERGI (dir.), Pellegrinaggi e santuari di San Michele nell'occidente medievale. Pèlerinages et sanctuaires de Saint-Michel dans l'Occident médiéval. Atti del secondo congresso internazionale dedicato all'Arcangelo Michele, Atti del XVI Convegno Sacrense (Sacra di San Michele, 26-29 settembre 2007), Bari, Edipuglia, "Biblioteca michaelica », 5, 2009, p. 207-239.

${ }^{7}$ Voir dans ce bulletin la contribution d'Aurélie HoudEBERT, « Amour et pèlerinage dans quelques romans d'aventure », p. 35-49.
} 
sont tôt détournées de leur pèlerinage vers Saint-Michel par la découverte d'une «relyke molt desirée / Et de totes dames honorée » ${ }^{8}$, un sexe masculin.

À ces nuances se sont ajoutées celles du temps et de l'espace : par parti-pris, seuls les pèlerinages chrétiens ont été envisagés, et c'est avant tout l'espace occidental qui a été arpenté, du $\mathrm{IV}^{\mathrm{e}}$ au $X \mathrm{XV}^{\mathrm{e}}$ siècle, avec une incursion jusqu’à Jérusalem. Chaque intervenant s'est ainsi efforcé d'expliquer le contexte particulier de son étude, pour cerner une pratique qui apparaît parfois comme hors du temps, rendue immuable par ses rituels, mais qui interroge justement, selon l'expression d'Aurélie Houdebert, « l’épaisseur du temps qui passe », la profondeur du temps vécu.

${ }^{8}$ Des Trois dames, in Recueil général et complet des fabliaux des XIII ${ }^{e}$ et XIV siècles, imprimés ou inédits, Anatole de MonTAIGLON et Gaston REYNAUd (éd.), Paris, Librairie des Bibliophiles, 1872-1890, t. IV, 1880, p. 128-132, v. 117-118. 